\title{
MEMOIR
}

\section{J. B. COLLIP}

\section{3-1965}

In Dr J. B. Collip's sudden death in London, Ontario, on 19th June 1965 at the age of 72, Canada lost one of her outstanding research scientists and pioneers in endocrinology. His many former students and colleagues lost a respected and sympathetic friend.

A graduate in Science from the University of Toronto (B.A. 1912, M.Sc. 1913, Ph.D. 1916), Collip's immediate appointment was in the Department of Biochemistry at the University of Alberta, in Edmonton, where he shared a large part of the teaching duties with a staff depleted by the war. Despite an onerous load of lecturing he proceeded to publish some twenty-five papers concerned with the comparative blood chemistry of vertebrates and invertebrates embracing such subjects as acid-base exchange, and the osmotic pressure and alkali reserve of the blood. In 1921 the award of a Rockefeller Travelling Fellowship allowed Collip to take a position in the Department of Pathological Chemistry at the University of Toronto to study the effect of $\mathrm{pH}$ on blood sugar under Professor J. J. R. Macleod and to join the group working on insulin. Banting and Best, at this time, had obtained definite evidence of hypoglycaemic activity in extracts of pancreas but the material gave rise to too severe local reactions at the site of injection to pursue clinical studies. Collip rapidly evolved a method of purification using gradient concentrations of alcohol which, in the final step, yielded a potent hypoglycaemic principle, yet essentially free of toxic impurities. The first clinical results on insulin were published in an epochmaking paper in March 1922 by Banting, Best, Collip, Campbell and Fletcher under the title 'Pancreatic extracts in the treatment of diabetes mellitus'. Over the short period of 2 years, fifteen fundamental papers and ten communicationabstracts on insulin and carbohydrate metabolism were published by the Toronto group and the impact was to spark a tremendous world-wide surge of interest in hormones and the endocrine glands. The experiences during the year at Toronto undoubtedly determined that Collip's future research interests were to be the separation and purification of hormones.

In 1922 he returned to Edmonton where he became Professor of Biochemistry and proceeded to take his M.D. degree. Here his fundamental work on the parathyroid glands was pursued, allowing him to publish in 1926 on 'The extraction of a parathyroid hormone which will prevent or control parathyroid tetany and which regulates the level of blood calcium'. Collip's approach to this problem was similar to that used in the preparation of insulin. The extracts were assayed on dogs following parathyroidectomy which exhibited a low blood calcium leading to tetany. Collip's often unorthodox approach to extraction procedures was well demonstrated when he noted that although saline or 
cold acid extraction was ineffective, hydrolysis with $5 \% \mathrm{HCl}$ led to the release of a highly potent fraction. As in the case of insulin he was able to prepare the active hormone which could be used in the treatment of patients. Collip's interest in calcium metabolism continued over the years and he was to make many contributions to this field. The modified method of estimation of blood calcium published with Clark in 1925 became a widely accepted routine method used in laboratories until very recently. His twenty papers on this subject at this time were reviewed in his Harvey Lecture, New York, of 1926.

At the age of 35 Collip moved to Montreal, accepting the senior appointment of Chairman and Head of the Department of Biochemistry at McGill University. The next 11 years were to be the most productive of his career and with a team of collaborators, which included David Thomson and Hans Selye, over 200 papers were published. Nearly every facet of endocrinology was investigated during these years when the subject was rapidly expanding throughout the world. Most projects centred around Collip, whose remarkable ability to handle large concentrates of glands, purify them to manageable proportions and separate out impurities and various hormone fractions, allowed him to record many new and important observations. Collip's restless and sometimes erratic techniques were designed to 'skim the cream off a problem' and then pass on to new fields. Many laboratories were to benefit, therefore, from these original contributions as they in turn proceeded to develop them in depth. Collip, from his experiences with insulin and parathormone, retained a strong urge to develop hormones which would ultimately be of benefit in treating patients. From the then confusing field of both oestrogenic and 'ovary stimulating substances' of the placenta, the group developed not only the isolation method for oestriol by J. S. L. Browne but also an orally active oestrogenic preparationEmmenin. Although of relatively weak potency, this preparation enjoyed a clinical popularity as an orally active oestrogen and was to be the forerunner of a much more potent conjugate-'Premarin'.

Interest turned from the chorionic and pituitary gonadotrophins to other trophic pituitary hormones. By 1933 Collip had prepared growth hormone essentially free of ACTH and TSH. The two latter hormones tended to run together in extracts but finally were separated. The preparation of purified TSH allowed many observations on its properties. The development of resistance to repeated injections and the finding that the blood of resistant animals would antagonize the hormone led to the concept of 'antihormones'. At the time these observations were exciting as they suggested to Collip that antihormones might be the physiological mechanisms to control all hormone activity. Although subsequent work established the non-specificity of these substances, this area of research did lead to the development of some interesting experimental models and helped to explain many of the observations concerning the relative ineffectiveness of some pituitary extracts in humans. ACTH was finally separated from pituitary extracts and established as a definite entity. In a 1933 paper it was noted that $\frac{1}{8} \mathrm{mg}$ total solid, given twice a day for 7 days, would repair the adrenal cortex of the hypophysectomized rat whereas larger doses did not show evidence of any other hormone activity in this preparation. Some clinical 
PLITE 1

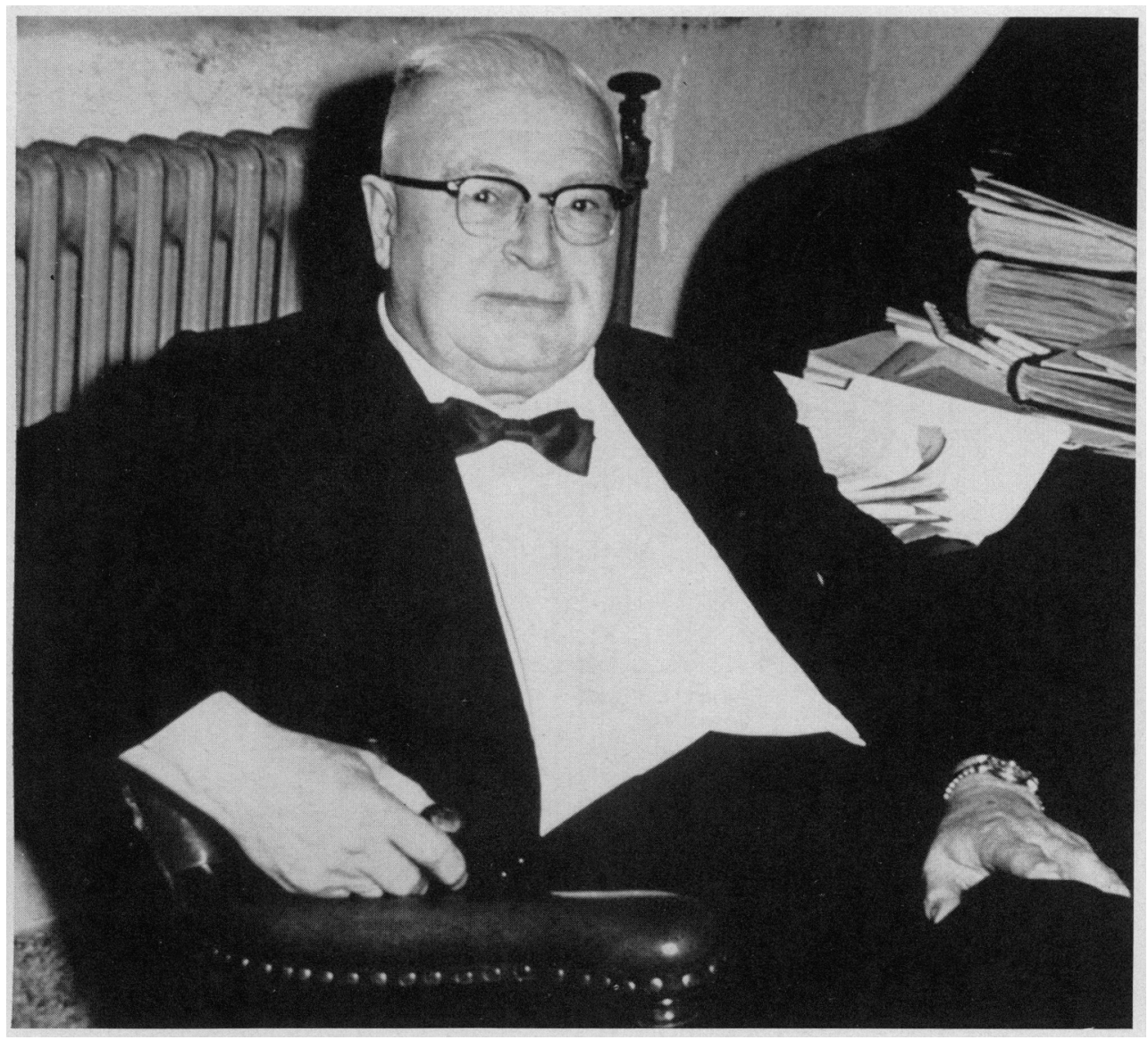

(Facing p. 168) 
studies were actually conducted with this purified ACTH but the conditions investigated did not show any beneficial response. (Unfortunately no patients suffering from the 'collagen diseases' were treated.) It is obviously impossible to review the many other interesting problems which were considered at this time. With the continuous preparation of extracts of all types by Collip and the availability of large numbers of hypophysectomized rats through Selye's operative skill the whole research group enjoyed a highly productive decade.

Dr Collip's contributions to science were widely acknowledged and he received many personal honours. He was elected to the Royal Society of London in 1933 and was a Member or Fellow in many other Societies or colleges in Canada, Britain and the United States. He was awarded a total of twelve honorary degrees from these countries. In 1938 Collip was to leave the laboratory bench to devote most of his time to the organization of war research as a member of a newly created Associate Committee for Medical Research of the National Research Council, Ottawa. Following the tragic death of the Chairman, Sir Frederick Banting, in 1942, Collip took over his duties. As this was the central committee responsible for the various aspects of military research in Canada the responsibilities were great. In addition he was appointed Medical Liaison Officer to Washington and was rewarded for his work of these years by decorations from both the Canadian and United States governments. Following the war Collip continued his administrative responsibilities as Director and Chairman of the Medical Advisory Committee of the National Research Council until his retirement at the age of 65 .

In 1941 Collip left the Department of Biochemistry at McGill to become the Gilman Cheyney Professor of Endocrinology in that University and Director of the Institute of Endocrinology. Although not participating personally in the research he was intensely interested and closely associated with many of the contributions from his laboratory which of necessity embraced many new areas of interest related to various military problems. Collip resigned from McGill in 1947 to become Dean of Medicine at the University of Western Ontario in London and to direct a Department of Medical Research in his own building, 'The Collip Medical Research Laboratory'. Here many graduate students were to benefit from training in his Department and join a research group active in many aspects of medical research. Although the days of searching for new hormones were over, Collip retained a keen interest in many of the endocrine problems being investigated. He retired as Dean in 1961 but continued as Director of his laboratory.

Collip never aspired to be a public figure and his modesty and inherent shyness made him reluctant to lecture or give papers, even to scientific audiences. At first meeting, his restlessness and switching from one topic to another gave the impression of abruptness, but one soon realized that behind this mannerism was a shyness and great personal charm. He was to influence deeply the lives of more than 100 associates who worked with him in the laboratory over the years. It is indeed fitting that in the place of honour at the entrance of the newly opened medical building at the University of Western Ontario a bronze basrelief profile of $\mathrm{Dr}$ Collip bears the following inscription: 'Pioneer in the 
Biochemistry of the Endocrine System and Dean of the Faculty of Medicine, 1947-1961. To this great Canadian in recognition of outstanding service to medical science and the welfare of mankind the research laboratories of this building are affectionately dedicated'.

R. L. NOBLE

University of British Columbia,

Vancouver. 1965 